\title{
OPTIMISING RIG DESIGN FOR SAILING YACHTS WITH EVOLUTIONARY MULTI-OBJECTIVE ALGORITHM
}

\author{
Mikołaj Pawłusik \\ Rafał Szłapczyński \\ Artur Karczewski \\ Gdańsk University of Technology, Poland
}

\begin{abstract}
The paper presents a framework for optimising a sailing yacht rig using Multi-objective Evolutionary Algorithms and for filtering obtained solutions by means of a Multi-criteria Decision Making method. A Bermuda sloop with discontinuous rig is taken under consideration as a model rig configuration. It has been decomposed into its elements and described by a set of control parameters to form a responsive model which can be used for optimisation purposes. Considering the contradictory nature of real optimisation objectives, a multi-objective approach has been chosen to address this issue. Once the optimisation process is over, a Multi-criteria Decision Making method based on a w-dominance relation is applied for filtering out the most interesting solutions from the obtained Pareto set. The proposed method has been implemented, and selected results are provided and discussed.
\end{abstract}

Keywords: Sailing yacht rig optimization,Bermuda sloop,Multi-Objective Evolutionary Algorithms (MOEA),Multi Criteria Decision Making (MCDM)

\section{INTRODUCTION}

Over the last few centuries, there has been a constant shift from design methods based on empiricism and experiments or even so-called rules of thumb towards a more analytical approach [1]-[3]. Instead of being content with the estimated characteristics of different phenomena (based on experience gained before), we want to know the reasons why those phenomena occur, in order to predict their characteristics with greater accuracy. Moreover, the last decades brought changes to the means of design in engineering. Designers, constructors and engineers use CAD/CAE software nowadays [2] instead of drawing gear and paper or a punch card computer in atransition time. The field of yacht design is no exception to the changes mentioned above. However, in some way it has remained unchanged regardless of computer software and the analytical approach involved in it. A yacht is a complex system composed of many subsystems that are strongly dependent on each other - a change made regarding one of them will cause a change regarding the others. Therefore, yacht design is an iterative process based on the trial and error approach. It is commonly referred to as a design spiral, in which issues are repeatedly considered in a predefined order, and each iteration comes closer to the satisfactory solution regarding all mutually dependent issues [2], [4]. The concept of a design spiral - where a designer starts from the outside and gets closer to the satisfactory solution (presented by the middle of the spiral) with subsequent encirclements - is presented in Fig. 1. 


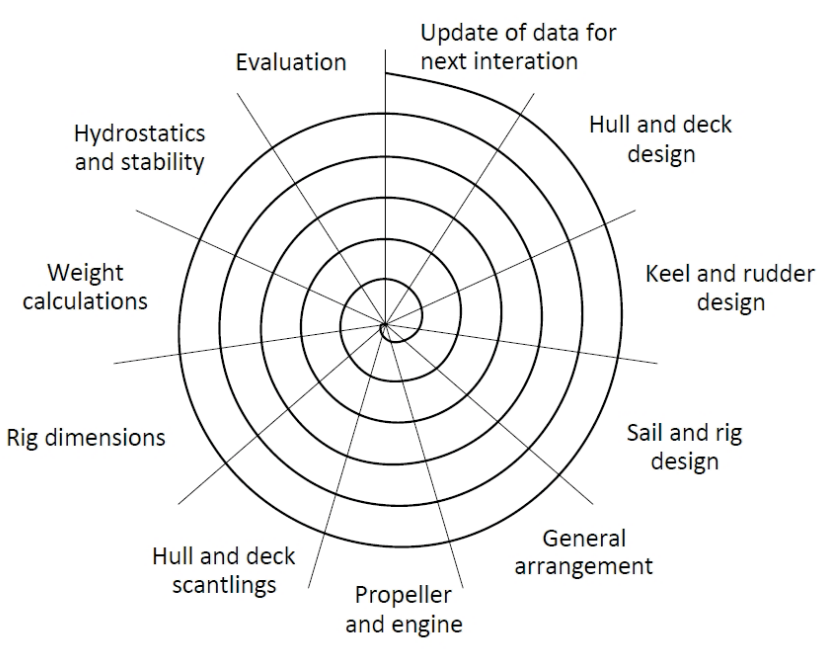

Fig. 1. Concept of design spiral illustrating the iterative nature of yacht design process [2]

A vast number of characteristics determine the shape of a sailing yacht seen by the observer at the end of design process. Aside from the fact of numerous, strongly dependent relations between yacht subsystems, many of above-mentioned characteristics are contradictory [2] - sail area vs. rig mass and its Vertical Centre of Gravity (VCG), interior space (volume) vs. small side surface subjected to wind pressure - to name but a few. Improving the design process involves finding a satisfactory balance between the conflicting characteristics mentioned above, which in turn requires solving a Multiobjective Optimisation Problem (MOP).

In general, optimisation is an issue being widely discussed in the field of yacht design. There are multiple works concerning Single-objective Optimisation Problems (SOPs) here. One of the most popular among them is the yacht speed optimisation carried out in a variety of ways - e.g. utilising Extreme Seeking [5], Pattern Search and STAR-CCM+ [6], Genetic Algorithms [7], numerical and experimental data to optimise up-wind sailing strategy [8] or parametric analysis and the lattice vortex method [9]. The works regarding MOPs in yacht design are relatively rare. They mostly focus on methods of selecting or optimising sails [10], [11], mast and rigging [12], [13] or both [14]. Among others, they propose an integrated sail-rig analysis method [14], sail optimisation method [10] [11], mast and rigging selection method [12] or optimal rig design method [13]. Yet, as for yacht rig optimisation, the existing works either apply a single-objective approach to optimisation (by aggregating various objectives into one goal function, usually in the form of a weighted average) or reduce the problem to a Multi-Criteria Decision Making (MCDM) one, where a solution is chosen from a predefined set [12].

Considering all of the above, we may conclude that there is still need for a multi-objective yacht rig optimisation method, which would simultaneously pursue multiple goals and look through the whole space of possible solutions. The current paper aims to fill this gap by proposing such a method. The method has been implemented and integrated within a software environment. Whilst the problem modelling in the method is simplified at this stage of work, the early simulation results confirm the method's potential and future usability.

The rest of the paper is organised as follows. In the next section, the design approach, software platform, as well as MOEA and MCDM are described briefly. Consequently, the optimisation problem is introduced - together with the rig model decomposition, its control parameters, optimisation objectives and constraints. Then, the optimisation and filtering algorithms are discussed. It is followed by the presentation of simulation results and their discussion. The paper is closed by summary and conclusion.

\section{PHYSICS BEHIND THE PROBLEM}

Fig. 2. presents a set of forces acting on a yacht while sailing upwind. A result of Apparent Wind acting on sails is Resultant Aerodynamic Force $\left(\mathrm{T}_{\mathrm{A}}\right)$ which in turn induce Resultant Hydrodynamic Force $\left(\mathrm{T}_{\mathrm{H}}\right)$ mainly due to presence of surface of lateral resistance (underwater part of hull, keel/ centreboard, rudder). $\mathrm{T}_{\mathrm{A}}$ might be decomposed to:

- Driving Force $\left(\mathrm{F}_{\mathrm{D}}\right)$, which gives the yacht a thrust causing it to move forward,

- Heeling Force $\left(\mathrm{F}_{\mathrm{p}}\right)$ - a side effect that causes the heel.

Then $\mathrm{T}_{\mathrm{H}}$ can be decomposed to:

- Hydrodynamic Drag Force (R) - which is an effect of mainly wave resistance and water viscosity,

- Hydrodynamic Lift Force $(\mathrm{N})$ which allows the yacht to stay on course.

$\mathrm{T}_{\mathrm{A}}$ is transmitted from the sails onto the mast (Fig. 4) and in order for mast to withstand the $\mathrm{T}_{\mathrm{A}}$ - standing rigging is introduced (Fig.9 \& Fig.10). It supports the mast and transfers the loads onto the hull. Leeward side of rig in the Fig. 4 has been omitted for the clarity - assuming no roll, the loads are transmitted by the windward side.

When looking at a yacht section, it can be observed that a Horizontal Component of Heeling Force $\left(\mathrm{F}_{\mathrm{PH}}\right)$ and Horizontal Component of Hydrodynamic Lift Force $\left(\mathrm{N}_{\mathrm{H}}\right)$ are the reason for a yacht heel, assuming coordination system with $\mathrm{X}$-axis parallel to the water surface and Y-axis pointing upwards. A righting moment (RM), generated both by Buoyancy Force (B) and Weight Force (W), keeps the yacht from capsizing (turning upside down). RM gives an information about how much wind the yacht can withstand and therefore is used for a yacht scantling. A value of RM corresponding to safe working angle (usually $30^{\circ}$ ) is taken into account. 


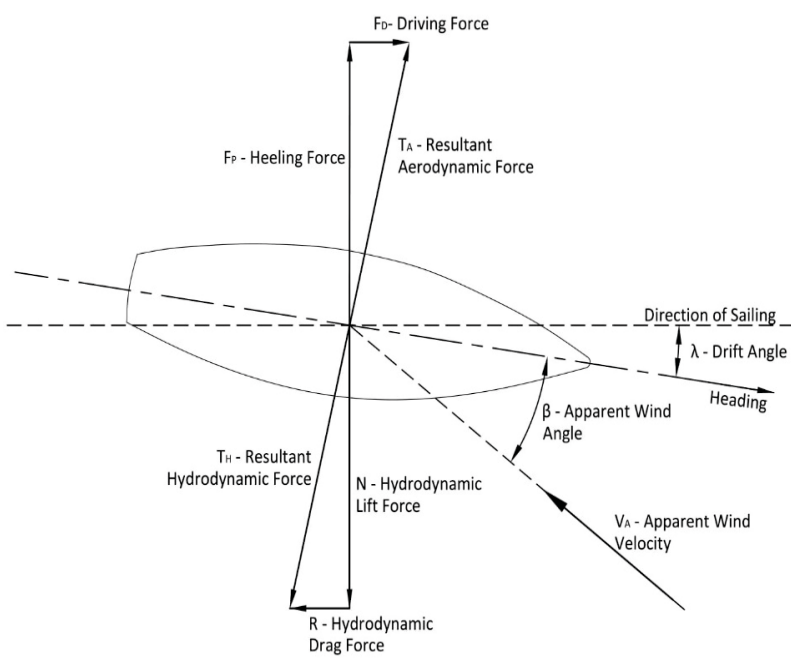

Fig. 2. Aero- and hydrodynamic forces acting on a sailing yacht while sailing upwind

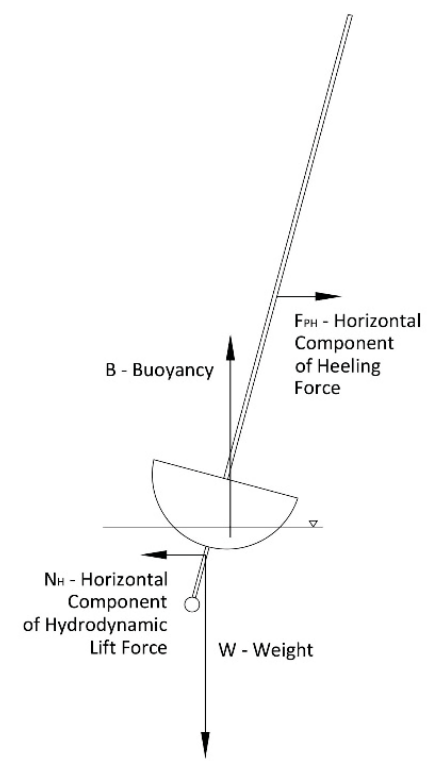

Fig. 3. Aero- and hydrodynamic forces acting on a sailing yacht - yacht section

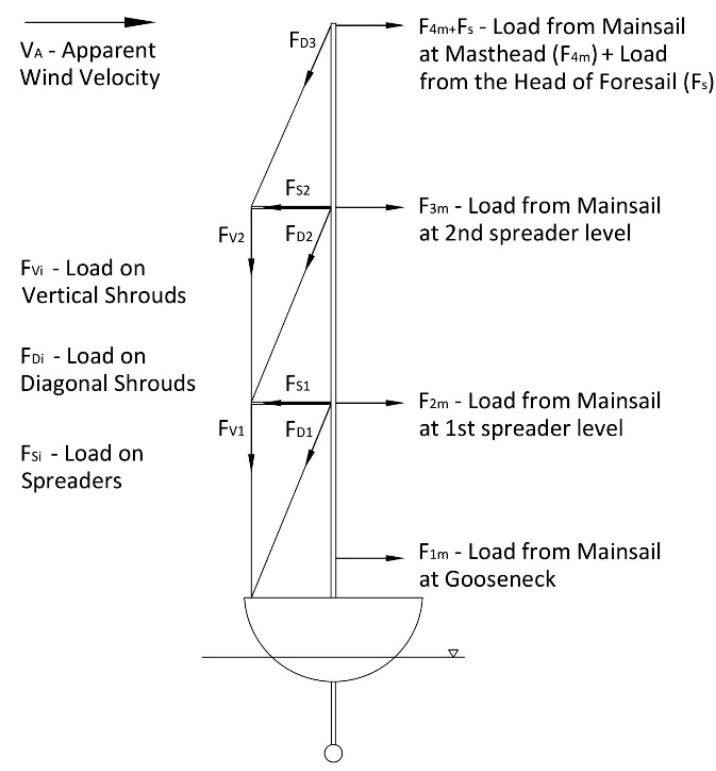

Fig. 4. Forces in the rig

When it comes to the rig scantling, a forces from sail loads in the standing rigging are evaluated (Fig.4), as well as the mast compression force and resulting required inertia moments to withstand buckling (deflection of the mast due to compression). Forces might be evaluates with a numerical method (e.g. FEM - Finite Elements Method) or analytically. In case of this paper an analytical approach has been chosen due to its easier employment in the selected software environment. The forces in transverse rigging shrouds \& spreaders (Fig.4), as well as in the mast sections - are evaluates with a method of joints, whereas forces in the stays are evaluated according to a Polish Register of Shipping Rules for rig scantling.

\section{RESEARCH METHODS AND SOFTWARE TOOLS}

After research regarding possible design approaches, it was decided to apply the Classification Rules issued by the Polish Register of Shipping (PRS) [15] regarding the rig design and scantling, due to the fact that most calculation might be solved within the chosen software platform - without a necessity of implementing FEM calculation (as for e.g. DNV-GL rules [16]).

Rhinoceros [17] was chosen as a basic platform for this project due to its relatively good modelling efficiency and a possibility to enhance it functionality by an easily accessible programming and parametric design which was crucial in this work. By parametric design, it is understood that designing does not involve operating on the model itself but on the set of control parameters by which the above-mentioned model is defined. It allows dynamic changes (even of major character) in the model and was essential in terms of automatising the optimisation process. The Rhinoceros platform is open for including multiple plug-ins. In this case, two such plug-ins are used: Grasshopper and Octopus.

Grasshopper [18] is a Rhinoceros dedicated plug-in adding the crucial feature of parametric design but also allowing the author to implement easily his own algorithm integrating a solution for all the issues undertaken in this work - described more extensively in the Problem section. As for Octopus [19], it is a robust optimisation plug-in, which offers the multi-objective optimisation feature by means of applying Multi-Objective Evolutionary Algorithms (MOEAs) [20].

The integrity of the software environment is a necessity, as the data are being transferred back and forth between Rhinoceros (which is utilised by Grasshopper as a platform for geometry modelling), Grasshopper within which or by which a majority of operation is performed (containing the main algorithm) and Octopus which implements the MOEA to Grasshopper. A simplified scheme of the main algorithm's flow is presented in Fig. 5. 


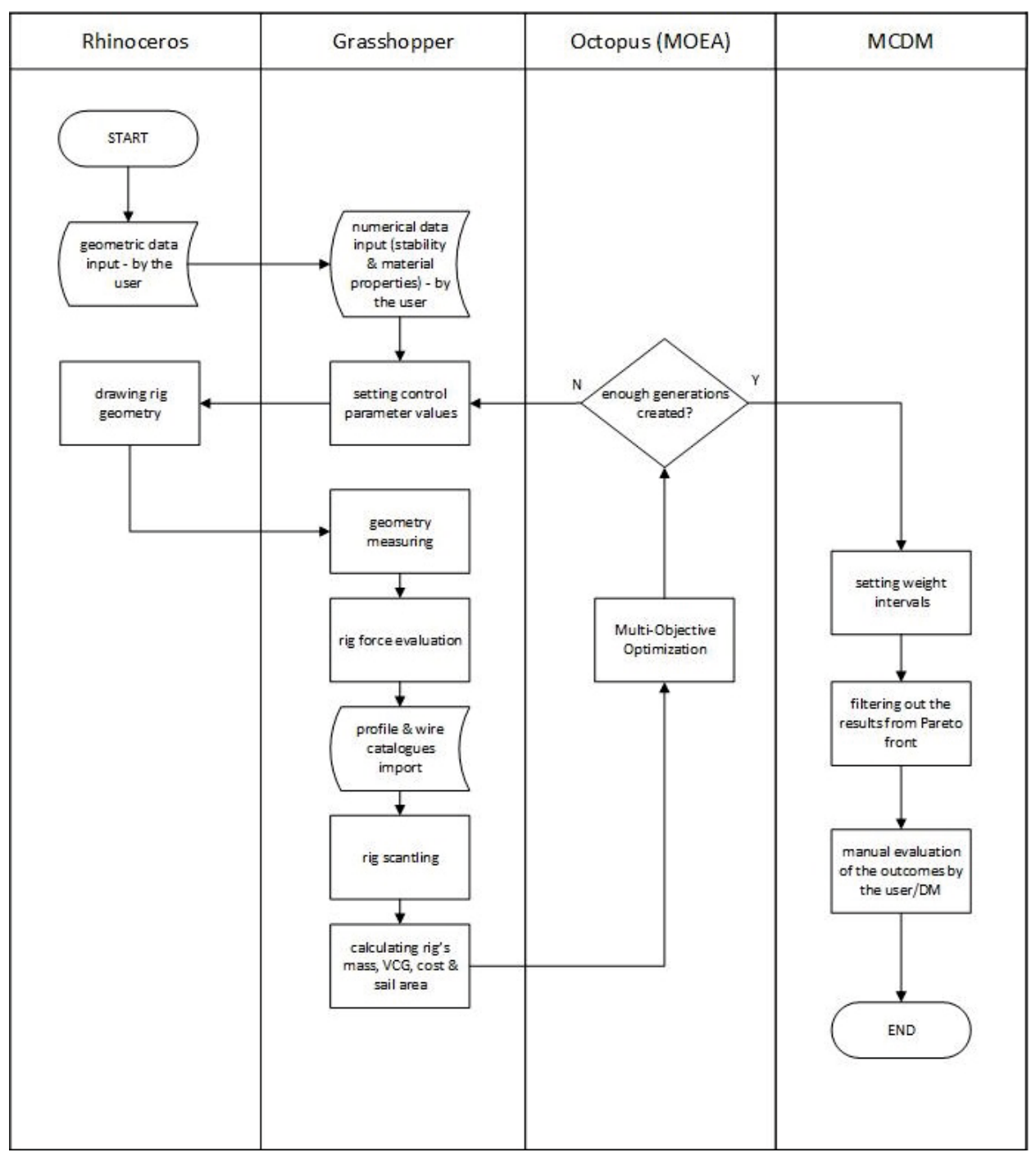

Fig. 5. Simplified flow chart of the method

The method requires the Decision Maker (DM) to choose a hull design and input the geometric (hull shape) and numeric data (stability properties). A material for mast profiles and spreaders has to be chosen as well (by default it is an aluminium alloy). If the DM decides on other material (e.g. steel/wood), there is a necessity to provide the algorithm with its properties in the form of Young's modulus and adequate profile catalogue. As for the standing rigging - stainless steel $1 \times 19$ wires are chosen by default - it can be modified as above, providing the algorithm with an alternative wire catalogue. The DM shall also provide the evolutionary optimisation parameters of SPEA2 algorithm [21] (coefficient for elitism and mutation probability, mutation and crossover rates, number of generations to be evaluated and a type of mutation). There is a possibility of modifying the control parameters' ranges if desired. At this point, an automatised part of the algorithm steps in - the DM starts to be a supervisor, until the optimisation process is over. However, if necessary there is a possibility of interfering with the optimisation process by means of a reference point (RP). After the optimisation process has been performed, there is a need to import the obtained Pareto set to a module responsible for MCDM. Once it is done, the weight intervals (ranges) are specified, and within seconds, based on w-dominance, a filtered set of solutions is obtained for further evaluation by the DM. It includes solutions which are most desirable in terms of given weight intervals. The size of the filtered-out $\mathrm{w}$-dominance front is determined by the width of weight ranges - the narrower they are, the smaller the filtered Pareto set is.

For the clarity a separate flow chart presenting how the computation is performed has been provided (Fig. 6). It covers the part of simplified flow chart (Fig. 5) - the excerpt from drawing rig geometry (Rhino) to rig scantling (Grasshopper). 


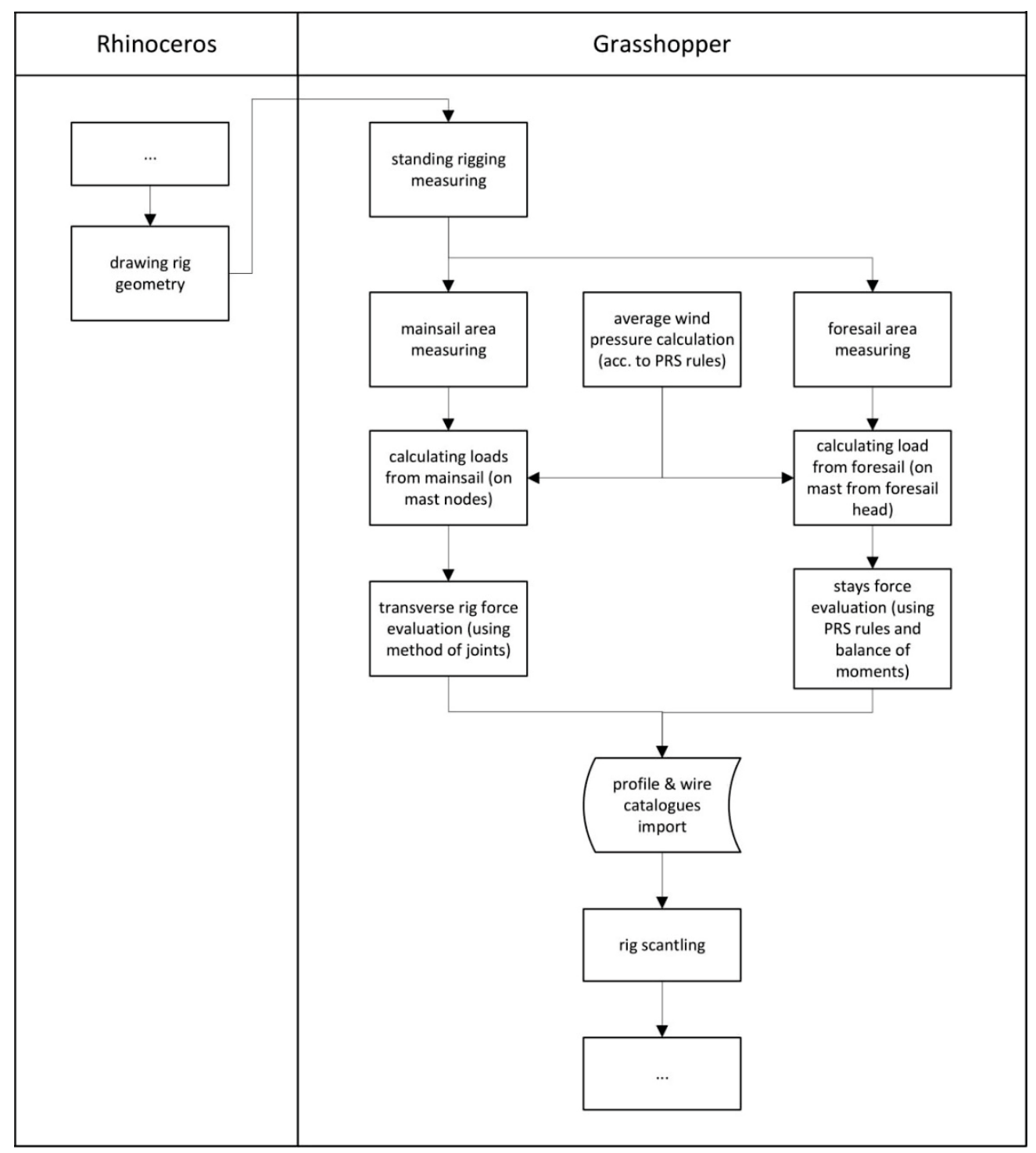

Fig. 6. Rig force evaluation flow chart

\section{MULTI-OBJECTIVE EVOLUTIONARY ALGORITHMS}

Whilst optimisation usually aims at finding one best possible solution, the situation significantly changes when we have more than one objective (goal function). In such case, we could have an infinite number of Pareto optimal solutions. A solution is called Pareto optimal or non-dominated if it is not possible to gain any improvements regarding one of the objectives without a sacrifice in terms of another [22]. To give an example - it is not possible to have a higher, more spacious interior with a given hull shape if will not accept a rise of side surface subjected to wind pressure. Fig. 7 illustrates the concept of a Pareto non-dominated solution in case of two objectives minimisation.

When it comes to multi-objective optimisation, there is no one objectively best solution, due to the contradictory nature of real optimisation problems. After the optimisation process, the user gets the collection of Pareto non-dominated solutions - a Pareto front - whose size depends on a generation size predefined at the beginning. The concept of a Pareto front in case of two objectives minimisation is illustrated in Fig. 8.

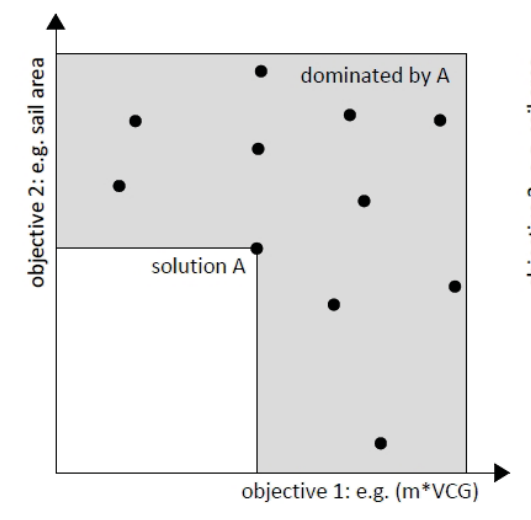

Fig. 7. Pareto non-dominated solution in case of two objectives minimisation [23]

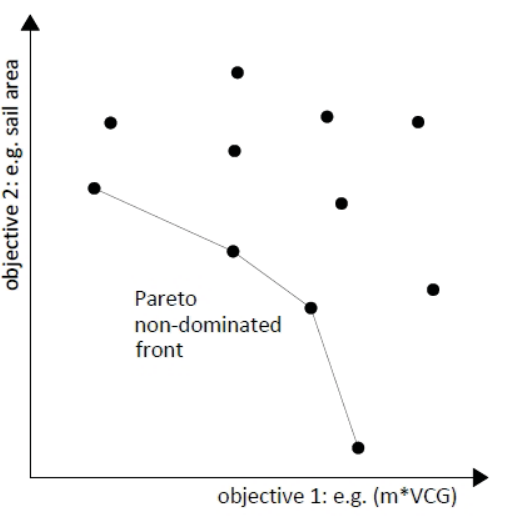

Fig. 8. Pareto non-dominated front in case of two objectives minimisation [23] 
Unfortunately, for many MOPs, neither analytical nor iterative deterministic solutions are available due to the particular MOP's complexity or large search space, which would result in an unacceptable computational time. Therefore, an indeterministic heuristic approach is often applied for such MOPs, namely Multi-Objective MetaHeuristics (MOMH). Of those, particularly successful are Multi-Objective Evolutionary Algorithms (MOEA), which combine random search and multiple genetic and problemdedicated operators (typical for Evolutionary Algorithms) with dominance relations and algorithms for sorting nondominated solutions. Owing to the above features, MOEAs are able to outrun analytical and iterative deterministic methods whilst returning a good approximation of a true Pareto set [22]. One of the classic and still competitive MOEAs is improved Strength Pareto Evolutionary Algorithm (SPEA II) [21], which is implemented in the Octopus optimisation plug-in [19] for the Rhinoceros platform.

\section{PREFERENCE-BASED MUTLI-CRITERIA DECISION MAKING (MCDM)}

As mentioned above, in case of multi-objective optimisation, the user obtains a set of non-dominated solutions which approximate the true Pareto set. In case of small Pareto sets, the user might check and evaluate the solutions manually. Usually, however, the Pareto set is too numerous for its manual evaluation, which would be too time-consuming and inefficient. Therefore, Multi Criteria
Decision Making (MCDM) tools are commonly used for filtering or ranking the results. Among others, MCDM may apply preferences specified by the DM. Taking into account the DM's preferences can be done in a number of ways [24]. The dominating one is that of a reference point (RP) - a point in the objective space which represents a solution that is desired and seems possible to be reached [25]. Other approaches to applying the DM's preferences include those of objective comparison, solution comparison, outranking, knee points and trade-offs [26]. Of those, the trade-off approach is particularly well suited for rig optimisation, where a DM is interested in a configurable balance between economic, efficiency and safety-related objectives. A subjective trade-off method utilising a weight-dominance relation (w-dominance) [27] is used in the paper to elicit and apply DM preferences to filter the obtained solutions.

\section{OPTIMISATION PROBLEM}

\section{YACHT MODEL AND RIG DECOMPOSITION}

For the current version of the method, a Bermuda sloop (Fig.9) - the most common rig nowadays - with a non-swept spreaders and discontinuous rig type (Fig. 10 \& Fig. 11) has been selected as a rig configuration. However, other rig configurations will also be considered and handled in the further development of the method.

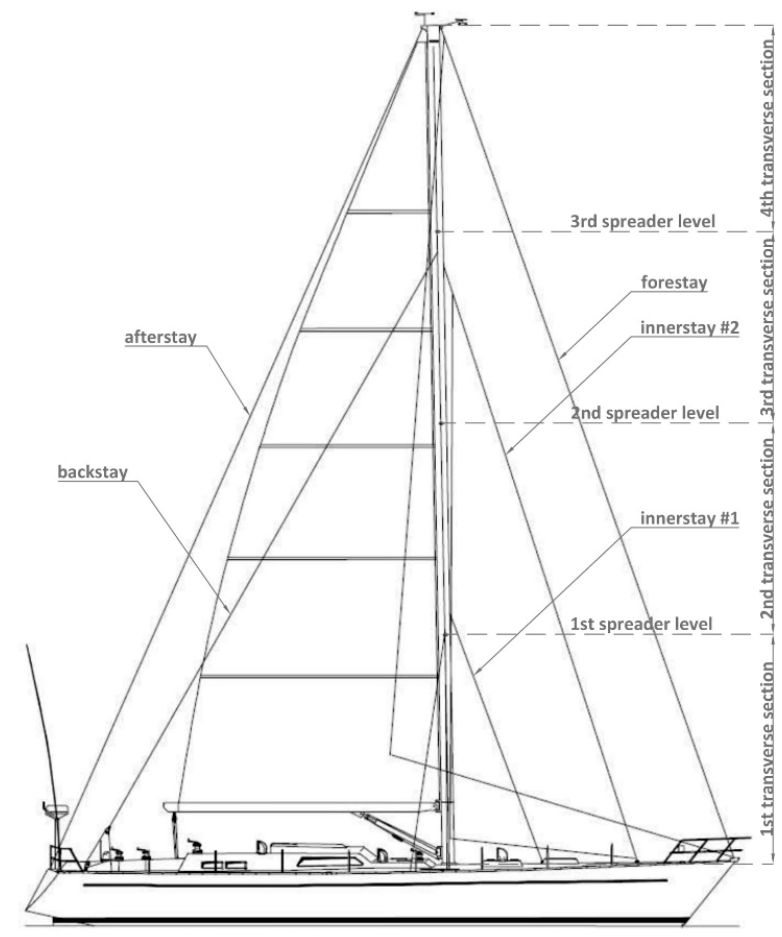

Fig. 9. Bermuda sloop with non-swept spreaders and backstay. The origin of the coordination system is located at the intersection of the yacht centreline and the projection of the transom tip (point farthest to the aft) to the deck level. The X-axis points forward, the Y-axis points to the portside (left when looking forward), and the Z-axis points upwards [28]

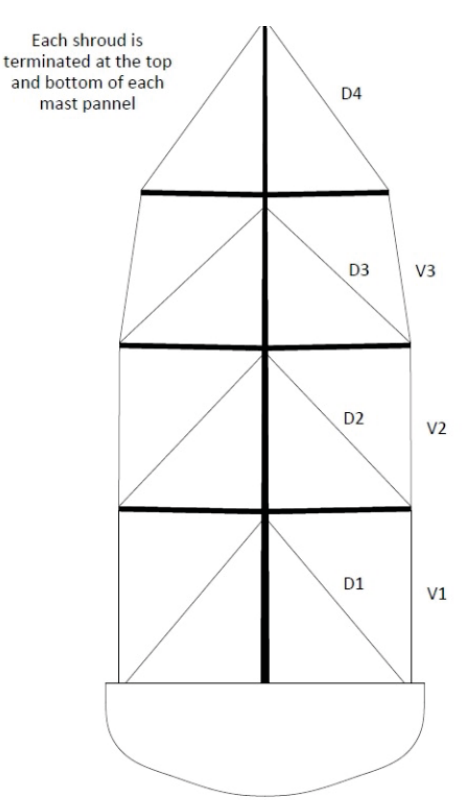

Fig. 10. Discontinuous rig, diagonal shrouds (D) and vertical shrouds $(V)$ are numbered going from the deck [29] 


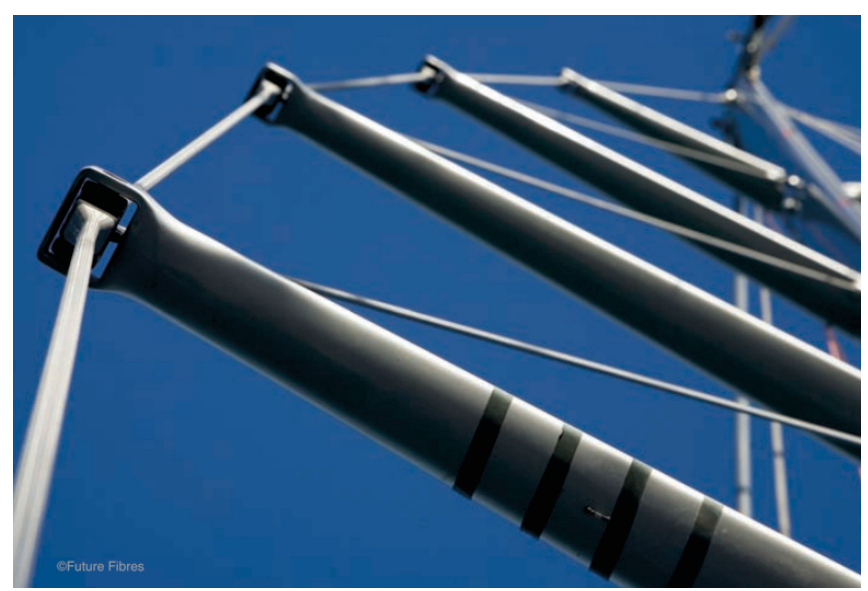

Fig. 11. Discontinuous rig [30]

The above-mentioned rig model (excluding the hull from Fig. 9, Fig. 10) might be decomposed into elements presented in Fig. 12.

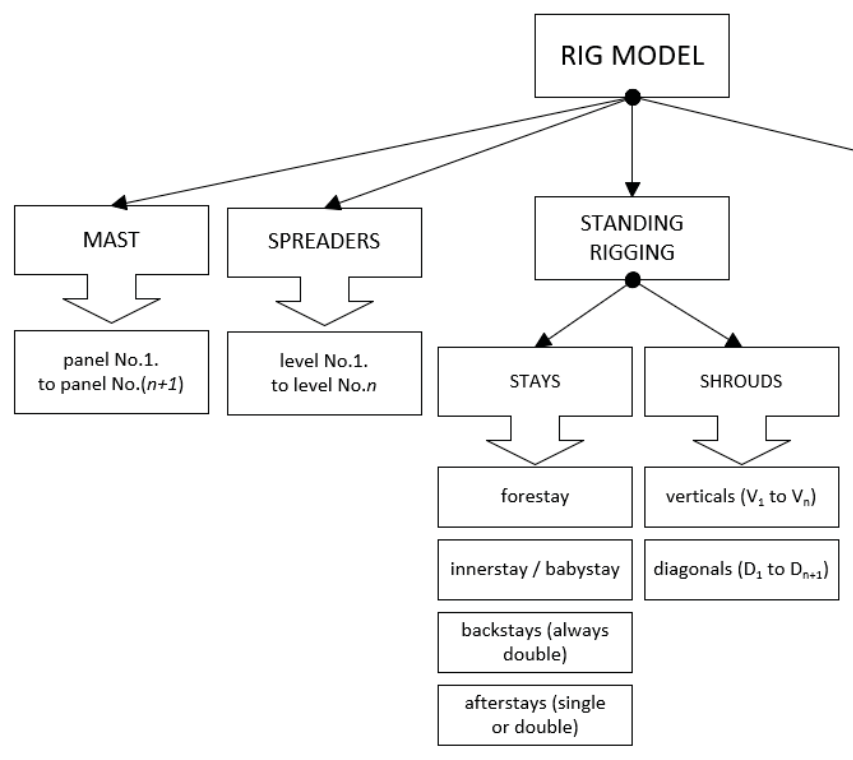

Figure 12. Decomposition of the rig model

\section{CONTROL PARAMETERS}

After decomposing the chosen rig configuration into its elements, it was necessary to describe it with a set of control parameters to obtain a responsive model - a model that dynamically adapts to the values of the control parameters that are being changed e.g. by the user. This approach is called parametric modelling and is widely utilised in yacht design as well as in multiple other fields. Owing to this, the user can introduce even major geometry modifications by changing values of control parameters instead of modifying the model itself.
The control parameters defined for describing the model (Fig. 9 and Fig. 10) are the following:

1. number of spreaders: $n_{s} \in\{1,2,3,4\}$, 2. (mast length over deck/ length of hull) ratio: $\frac{l_{\text {m.od }}}{L_{H}}$
$=\{1.15,1.16,1.17, \ldots, 1.50\}$,

3. mast 1st transverse section coefficient: $k_{1 t}=\{1.00,1.01,1.02, \ldots, 1,50\}$,

4. mast 2nd transverse section coefficient: $k_{2 t}=\{1.00,1.01,1.02, \ldots, 1,50\}$,

5. number of innerstays present (counting from deck): $n_{i s p} \in\{1,2,3,4\}$ and $n_{i s p} \leq n_{s}$.

Usually, length of $1^{\text {st }}$ mast transverse section (of $2^{\text {nd }}$ often as well) differs from the length of other mast transverse sections, thus $\mathrm{k}_{1 \mathrm{t}}$ and $\mathrm{k}_{2 \mathrm{t}}$ has been introduced - determining the length of the $1^{\text {st }}$ and $2^{\text {nd }}$ section regarding other sections' length.

\section{OPTIMISATION OBJECTIVES}

A designer's purpose is to obtain an efficient rig, which means a rig that will produce enough thrust for a considered boat with possibly low mass and VCG. Usually its cost should be within the budget specified by the client. This has been reflected in the presented method's framework. The mass and VCG have been combined into one objective: in terms of the overall yacht's CG, saving in mass is indifferent if compensated by rise of VCG (as well as the other way around). For the abovementioned reason, the first objective is minimisation of mass multiplied by VCG. The second one refers to the rig's capability to produce thrust, and at that development stage (assuming triangle-shaped sails), a sail area has been chosen as an objective. The third objective is connected with the cost of the rig - a set of offers and price lists have been gathered from rigging companies, and based on analysis of them, a rig material cost estimation module has been implemented into the algorithm. It calculates the cost on the basis of price lists - either found on the company's websites or deducted and interpolated from the set of offers received.

To sum up, the objectives are:

1. minimising $(\mathrm{m} * \mathrm{VCG})[\mathrm{kg} \cdot \mathrm{m}]-$ as an indicator of gain or loss regarding the yacht's stability,

2. maximising the sail area $\left[\mathrm{m}^{2}\right]-$ as an indicator of gain or loss regarding the rig's efficiency,

3. minimising the cost of rig elements (mast \& spreader profiles, spreader fittings, wires, terminals and rig screws for the standing rigging) [EUR]. 
The above-listed objectives are mutually divergent. E.g., for a specified hull shape, a gain in sail area will cause a rise of mass and usually also a rise of VCG (a loss in terms of the $1^{\text {st }}$ objective) as well as cost growth (a loss regarding the $3^{\text {rd }}$ objective). Similarly, minimising the mass and VCG can only be done by sacrifice in terms of sail area or a significant rise in cost (when shifting from aluminium to carbon spars and from ordinary stainless steel wires to rods, aramid or $\mathrm{PBO}$ wires).

\section{OPTIMISATION CONSTRAINTS}

For the optimisation problem to be solved in the paper, the constraints are stated in one of three ways:

- as allowing the optimisation algorithm to manipulate only a chosen group of parameters describing the rig model,

- as directly specified intervals (ranges) of the abovementioned chosen group of parameters (control parameters),

- as dependencies fed to the optimisation part of algorithm. The first two groups were described in the Control

Parameters section. Constraints from the last group are listed below:

- the required transverse inertia moment $\left(\mathrm{I}_{\mathrm{xx}}\right)$ of the mast profile is smaller than the $\mathrm{I}_{\mathrm{xx}}$ of the biggest mast profile fed to the algorithm,

- the required longitudinal inertia moment $\left(\mathrm{I}_{\mathrm{yy}}\right)$ of the mast profile is smaller than the $\mathrm{I}_{\mathrm{yy}}$ of the biggest mast profiles in the catalogue fed to the algorithm,

- the calculated breaking load (BL) of each line is lower than the minimum BL of the biggest line in the catalogue fed to the algorithm.

The above-mentioned constraints aim at excluding solutions that are infeasible taking into account given components (mast profiles or wires) and avoiding a situation when loads exceed maximum elements' strength - which could lead to the rig damage [31].

\section{OPTIMISATION ALGORITHM AND PREFERENCE- BASED FILTERING OF RESULTS}

The algorithm's input data might be divided into two groups: geometric (that are being imported from Rhinoceros) and numeric (which have to be specified in Grasshopper). In case of a rig arrangement (omitting a sail balance at this preliminary stage of development), the geometric data are limited to the yacht centreline and side contour at the deck level (Fig.13 \& Fig.18). When it comes to numeric data, they are characteristics regarding yacht stability and mast profile material for scantling purposes (fitted to the PRS rig scantling algorithm [15]). The user can either choose to give the righting moment at 30-degree heel and ballast coefficient (defined by PRS regarding the type of ballast) or displacement and maximum righting lever up to 60-degree heel as stability data. For mast material data, it is possible to choose from a few predefined materials or to input the chosen material's Young's modulus.
As for the main algorithm's flow, it is as follows. Assuming that the case of a specific yacht is considered and the decision regarding hull choice has been made, it is required to feed a deck outline together with a yacht axis as geometric data and stability properties as numeric data. Subsequently, catalogues of mast \& spreader profiles have to be indicated. It should be noticed that the above-mentioned catalogues might significantly limit the solution space (due to optimisation constraints described earlier). Following this, any interaction with the user is no longer required - the rest of the operations are performed automatically. Based on the control parameters described earlier (and listed in the flow chart), subsequent elements' geometries of the rig are drawn step by step - as for drawing of some, the presence of others are necessary (e.g. drawing the verticals requires the presence of spreaders).

Having the rig geometry created as a model for calculation, calculations for the matter of rig scantling are performed. The mast compression force and the resulting required inertia moments are calculated - for the purpose of mast profile selection as well as rig elements' normal forces for the need of standing rigging wire selection. Having scantling done, the algorithm evaluates quantities for the optimisation algorithm - rig's mass, VCG and cost (sail area has been determined during the wire selection). At this point, the algorithm may either go back to the control parameters to change their values and create another individual and continue the optimisation process or terminate it if the assumed number of generations has been reached.

Once the main optimisation process is completed, a preference-based MCDM method is used for filtering those results, which addresses the DM's best interest. The method applies the w-dominance relation [27], where the DM specifies weight intervals (ranges) regarding each optimisation objective (goal function). The $\mathrm{w}$-dominance relation extends Pareto dominance in such a way that some of non-dominated solutions in the strict Pareto sense will be w-dominated and thus eliminated.

\section{SIMULATION RESULTS}

For the sake of presentation, two simulations - with two different sets of input data - have been carried out, and each of them has been filtered out with MCDM based on two sets of weight ranges. For the evaluation, two different hull designs were taken into account (different size - length over all (LOA) and different stability properties). Fig. $13 \&$ Table 1 present the 1st set of data (for 33-foot hull) fed to the algorithm. Next, Fig. 14 illustrates the obtained Pareto set, and Table 2 $\&$ Table 3 present the weight ranges for the MCDM regarding the $1^{\text {st }}$ set of data. Fig.15 \& Fig.16 present the solution sets obtained after MCDM, and Fig. 17 presents the individuals of the filtered set. 


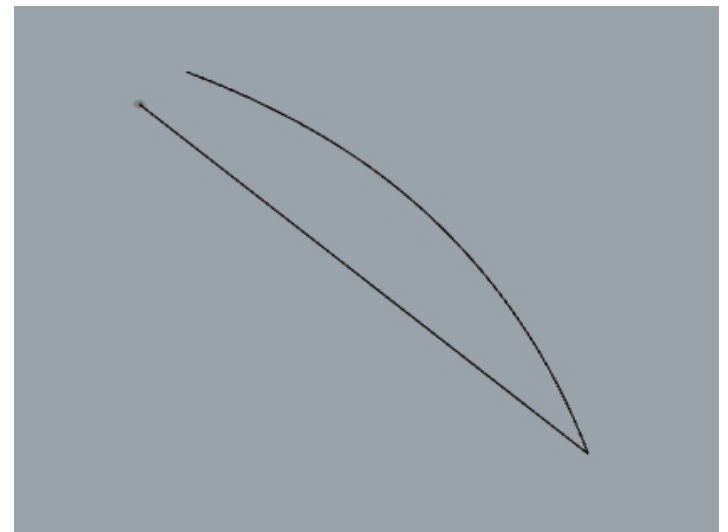

Fig. 13. $1^{\text {st }}$ set of geometric data - centreline and side contour at the deck level (33' hull), own source

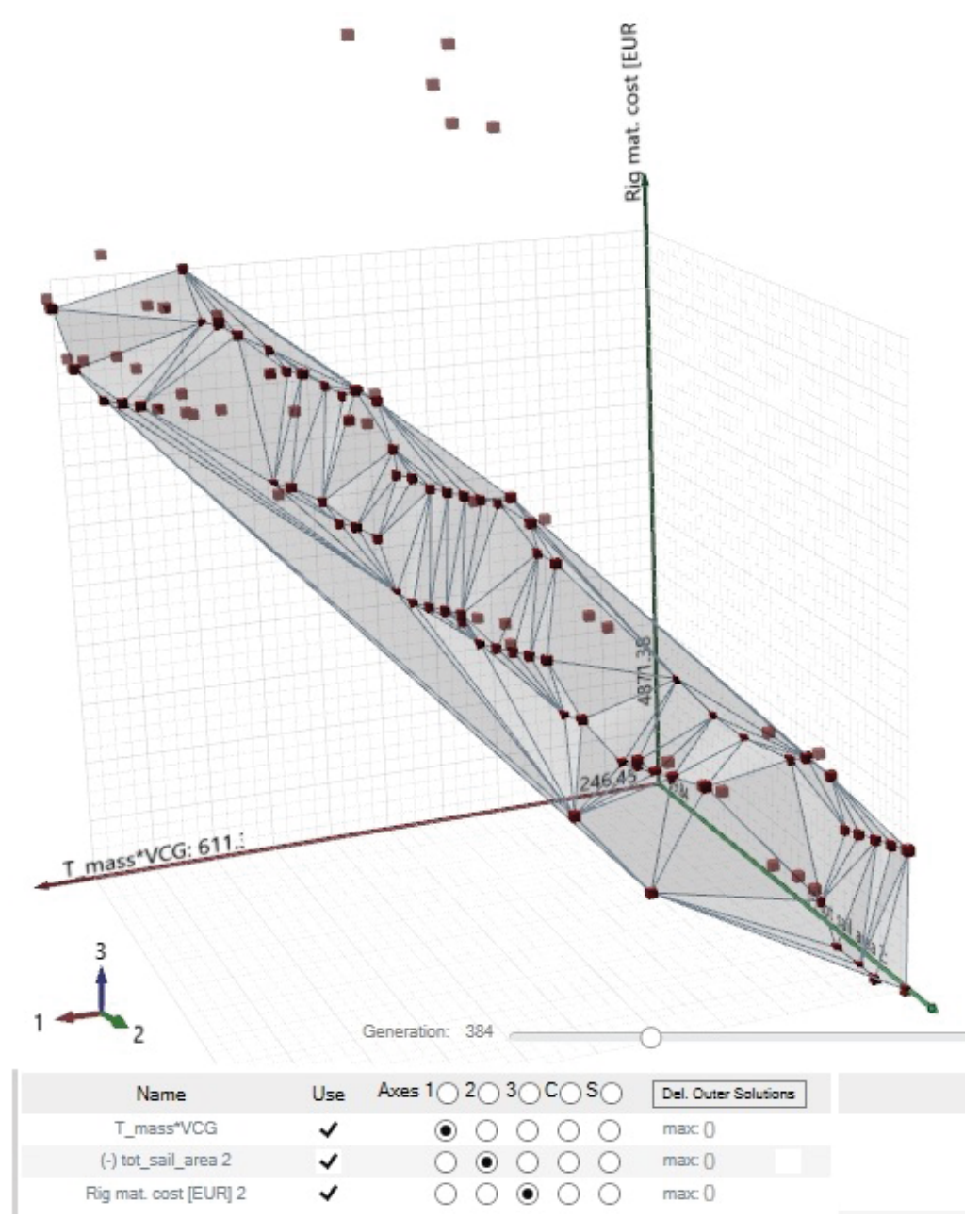

Fig. 14. Pareto set obtained for $1^{\text {st }}$ set of data

Tab. 1. $1^{\text {st }}$ set of numeric data (33' hull), own source

\begin{tabular}{|c|l|c|}
\hline No. & \multicolumn{1}{|c|}{ Characte-ristic } & Value \\
\hline 1 & LOA $[\mathrm{m}]$ & 10.07 \\
\hline 2 & B $[\mathrm{m}]$ & 3.51 \\
\hline 3 & RM30 $[\mathrm{kNm}]$ & 43.00 \\
\hline 4 & ballast coeff. $\left(\mathrm{k}_{\mathrm{t}}\right)[-]$ & 1.50 \\
\hline
\end{tabular}

Tab. 3. Set (B) of weight ranges for 1st set of data

Tab. 2. Set (A) of weight ranges for 1st set of data

\begin{tabular}{|c|c|c|}
\hline No. & goal function & weight range \\
\hline 1 & $\left(\mathrm{~m}^{\star} \mathrm{VCG}\right)$ & $\langle 0.5,1\rangle$ \\
\hline 2 & sail area & $\langle 0.5,1\rangle$ \\
\hline 3 & cost & $\langle 0.5,1\rangle$ \\
\hline
\end{tabular}

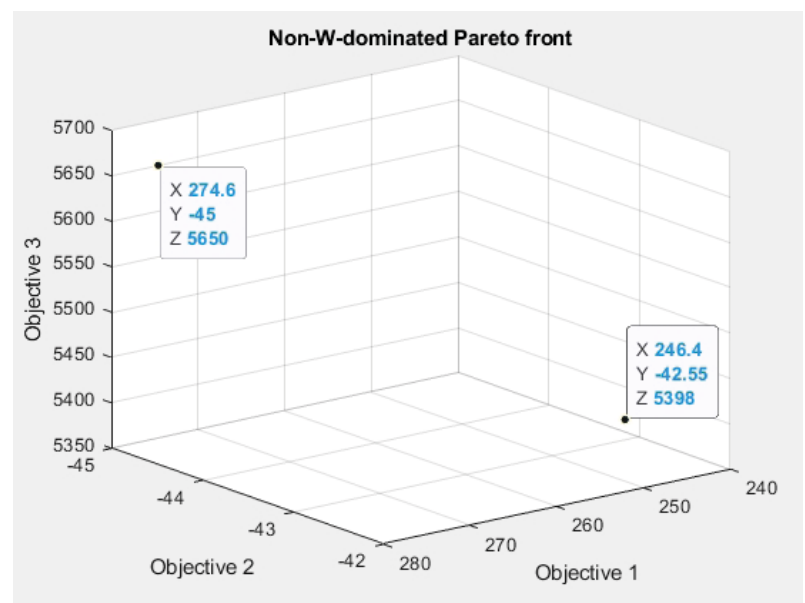

Fig. 15. Solution set obtained for $1^{\text {st }}$ set of data and (A) set of weight ranges

\begin{tabular}{|c|c|c|}
\hline No. & goal function & weight range \\
\hline 1 & $\left(\mathrm{~m}^{*} \mathrm{VCG}\right)$ & $\langle 0.8,1\rangle$ \\
\hline 2 & sail area & $\langle 0.8,1\rangle$ \\
\hline 3 & cost & $\langle 0.8,1\rangle$ \\
\hline
\end{tabular}

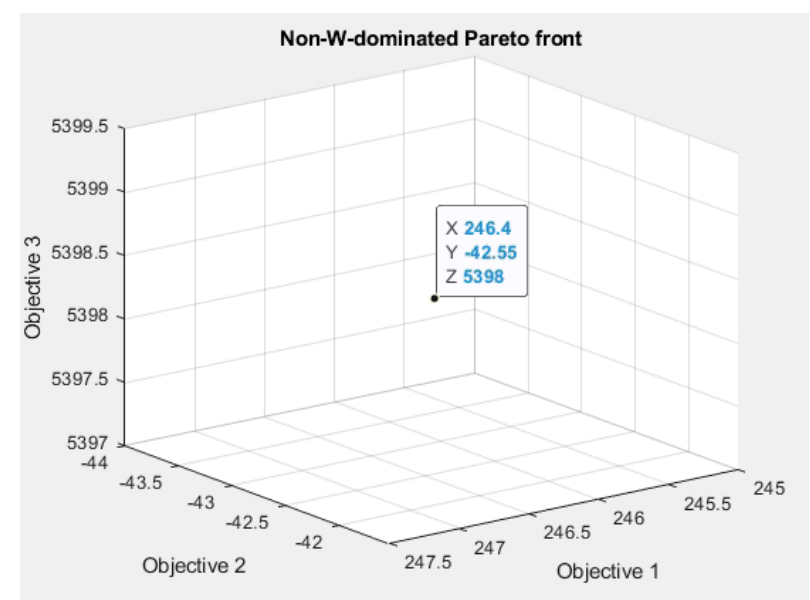

Fig. 16. Solution set obtained for $1^{\text {st }}$ set of data and (B) set of weight ranges 


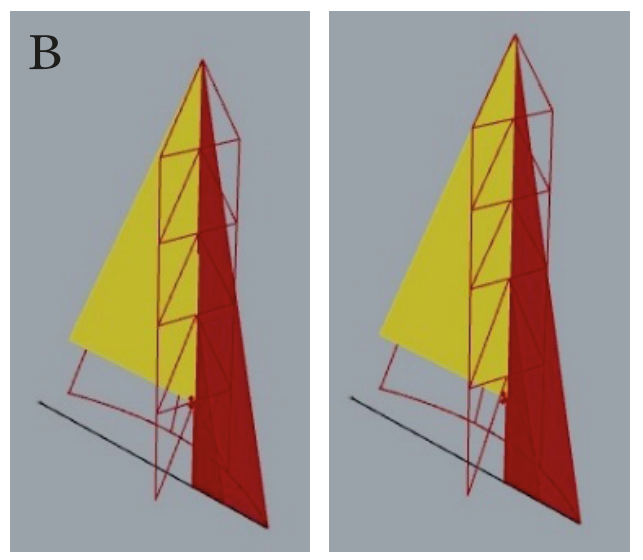

The $2^{\text {nd }}$ set of input data refers to $\sim 47$-foot hull. Its characteristics - input data for the algorithm - are presented in Fig.18 \& Table 4. Fig.19 illustrates the obtained Pareto set, and Table $5 \&$ Table 6 present the weight ranges for the MCDM regarding the $2^{\text {nd }}$ data set. Fig. 20 \& Fig. 21 present the solution sets obtained after MCDM, and Fig. 22 presents the individuals of the filtered set.

Fig. 17. Filtered solutions from the Pareto set for 1st set of data, given (A) set of weight ranges, sorted by value of 1 st goal function increasing, given $(B)$ set of weight range solution: 1st from left remains

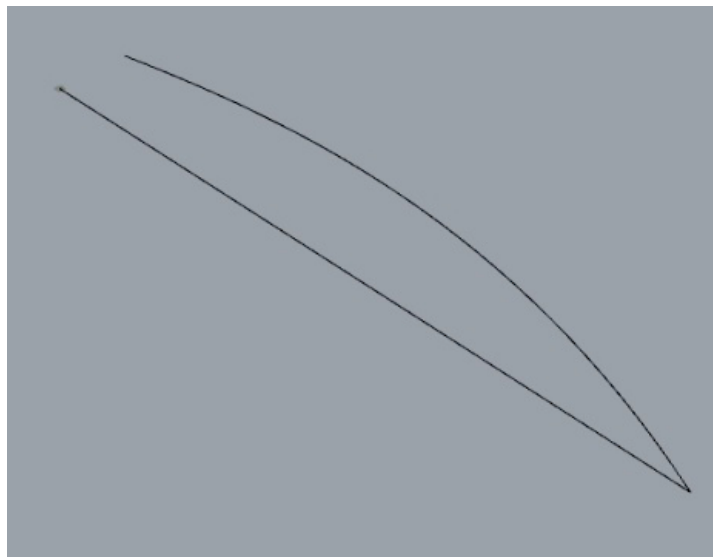

Fig. 18. $2^{\text {nd }}$ set of geometric data - centreline and side contour at the deck level (47' hull), own source

Tab. 4. $2^{\text {nd }}$ set of numeric data (47' hull), own source

\begin{tabular}{|c|l|c|}
\hline No. & \multicolumn{1}{|c|}{ Characteristic } & Value \\
\hline 1 & LOA $[\mathrm{m}]$ & 14.38 \\
\hline 2 & B $[\mathrm{m}]$ & 4.36 \\
\hline 3 & RM30 $[\mathrm{kNm}]$ & 123.00 \\
\hline 4 & ballast coeff. $\left(\mathrm{k}_{\mathrm{t}}\right)[-]$ & 1.50 \\
\hline
\end{tabular}

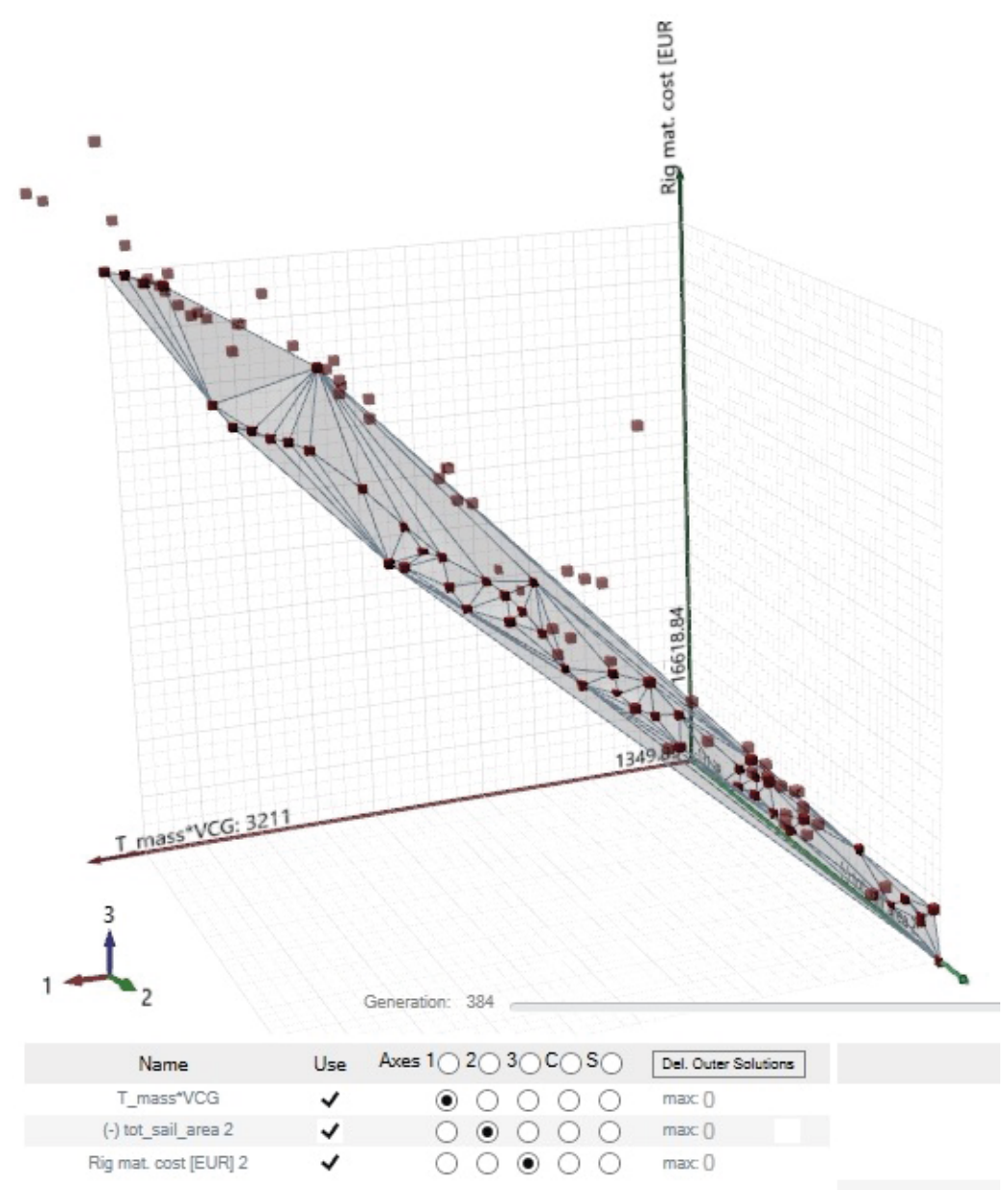

Fig. 19. Pareto set obtained for $2^{\text {nd }}$ set of data ( $47^{\prime}$ hull)

Tab. 5. Set (A) of weight ranges for the $2^{\text {nd }}$ data set

\begin{tabular}{|c|c|c|}
\hline No. & goal function & weight range \\
\hline 1 & $\left(\mathrm{~m}^{\star} \mathrm{VCG}\right)$ & $\langle 0.5,1\rangle$ \\
\hline 2 & sail area & $\langle 0.5,1\rangle$ \\
\hline 3 & cost & $\langle 0.5,1\rangle$ \\
\hline
\end{tabular}

Tab. 6. Set (B) of weight ranges for the $2^{\text {nd }}$ data set

\begin{tabular}{|c|c|c|}
\hline No. & goal function & weight range \\
\hline 1 & $\left(\mathrm{~m}^{*} \mathrm{VCG}\right)$ & $\langle 0.8,1\rangle$ \\
\hline 2 & sail area & $\langle 0.8,1\rangle$ \\
\hline 3 & cost & $\langle 0.8,1\rangle$ \\
\hline
\end{tabular}




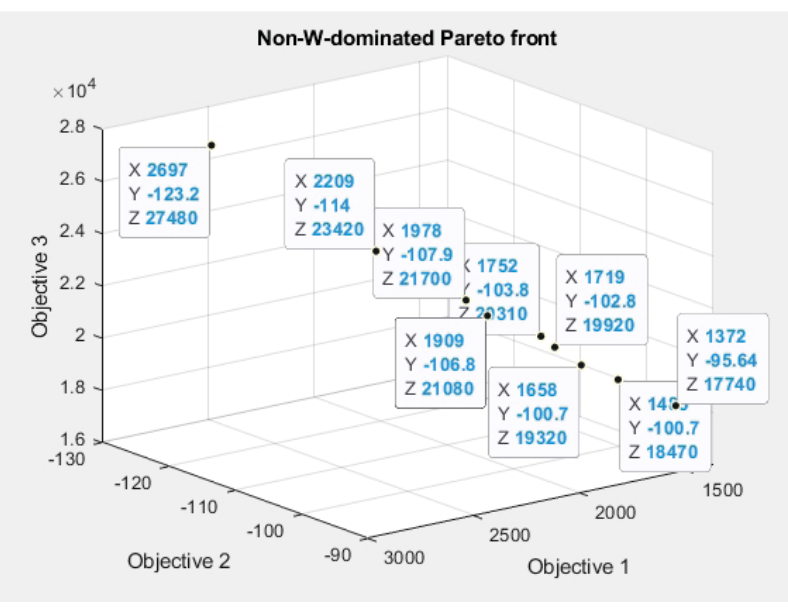

Fig. 20. Solution set obtained for $2^{\text {nd }}$ set of data and $(A)$ set of weight ranges

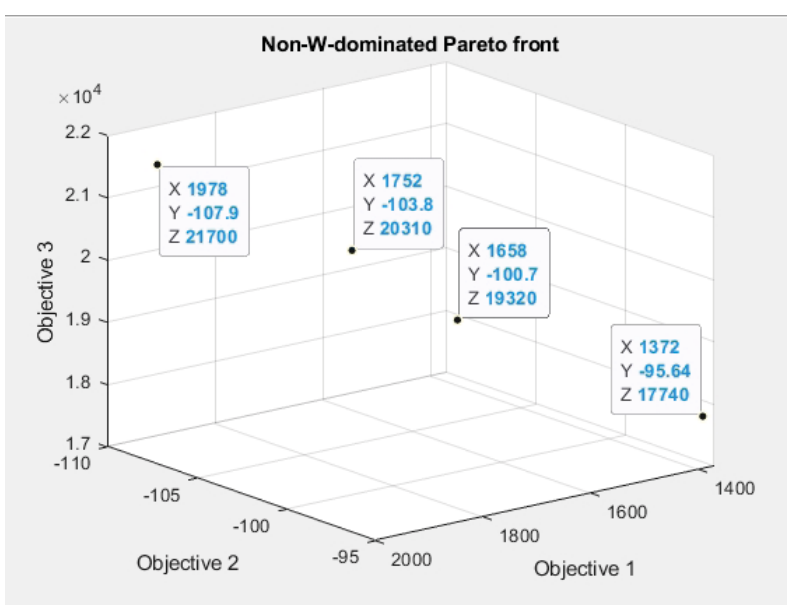

Fig. 21. Solution set obtained for $2^{\text {nd }}$ set of data and $(B)$ set of weight ranges

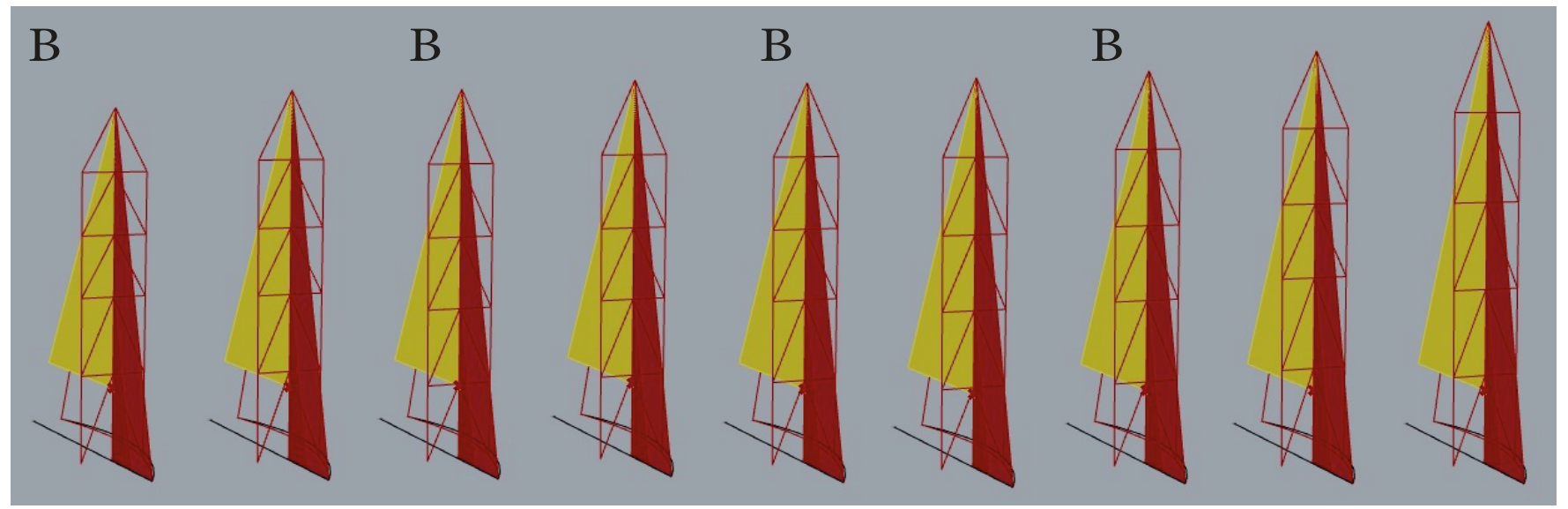

Fig. 22. Filtered solutions from the Pareto set for 2 nd set of data, given (A) set of weight ranges, sorted by value of 1 st goal function increasing, given $(B)$ set of weight range solutions: 1 st, $3 \mathrm{rd}$, 5th and 7 th from left remains

As the solution space for $2^{\text {nd }}$ set of data consists of many similar solutions - where a difference is difficult to notice they have been compared in the Table 7.

Tab. 7. Comparison of filtered solutions from the Pareto set for 2 nd set of data, given (A) set of weight ranges, sorted by value of 1 st goal function increasing, given (B) set of weight range solutions (grey rows)

\begin{tabular}{|c|c|c|c|c|c|c|}
\hline $\begin{array}{c}\text { solution } \\
\text { (Obj.1.;Obj.2.;Obj.3.) }\end{array}$ & $\begin{array}{c}1^{\text {st }} \text { mast } \\
\text { transverse } \\
\text { section length } \\
{[\mathrm{m}]}\end{array}$ & $\begin{array}{c}2^{\text {nd }} \text { mast } \\
\text { transverse } \\
\text { section length } \\
{[\mathrm{m}]} \\
\end{array}$ & $\begin{array}{c}3^{\text {rd }} \text { mast } \\
\text { transverse } \\
\text { section length } \\
{[\mathrm{m}]} \\
\end{array}$ & $\begin{array}{c}4^{\text {th }} \text { mast } \\
\text { transverse } \\
\text { section length } \\
{[\mathrm{m}]}\end{array}$ & $\begin{array}{c}5^{\text {th }} \text { mast } \\
\text { transverse } \\
\text { section length } \\
{[\mathrm{m}]} \\
\end{array}$ & $\begin{array}{c}\text { overall } \\
\text { mast length } \\
{[\mathrm{m}]}\end{array}$ \\
\hline $1372 ;-95,64 ; 17740$ & 4,23 & 3,67 & 2,88 & 2,88 & 2,88 & 16,54 \\
\hline $1484 ;-100,7 ; 18470$ & 4,31 & 3,66 & 3,09 & 3,09 & 3,09 & 17,24 \\
\hline $1658 ;-100,7 ; 19320$ & 3,66 & 3,59 & 3,34 & 3,34 & 3,34 & 17,27 \\
\hline $1719 ;-102,8 ; 19920$ & 3,96 & 3,61 & 3,32 & 3,32 & 3,32 & 17,53 \\
\hline $1752 ;-103,8 ; 20310$ & 4,00 & 3,82 & 3,29 & 3,29 & 3,29 & 17,69 \\
\hline $1909 ;-106,8 ; 21080$ & 3,88 & 3,66 & 3,53 & 3,53 & 3,53 & 18,13 \\
\hline $1978 ;-107,9 ; 21700$ & 4,05 & 3,91 & 3,43 & 3,43 & 3,43 & 18,25 \\
\hline $2209 ;-114,0 ; 23420$ & 4,63 & 4,28 & 3,40 & 3,40 & 3,40 & 19,11 \\
\hline
\end{tabular}


The w-dominance method's filtering efficiency might be observed by comparing the size of the Pareto set and the filtered solution set. The comparison is presented in Table 8 .

Tab. 8. Pareto set size and filtered set size comparison

\begin{tabular}{|l|c|c|c|}
\hline & $\begin{array}{c}\text { Pareto } \\
\text { set } \\
\text { size }\end{array}$ & $\begin{array}{c}\text { Number of } \\
\text { non-dominated } \\
\text { solutions for the } 1^{\text {st }} \\
\text { set of weight ranges } \\
(A)\end{array}$ & $\begin{array}{c}\text { Number of } \\
\text { non-dominated } \\
\text { solutions for the } 2^{\text {nd }} \\
\text { set of weight ranges } \\
(B)\end{array}$ \\
\hline $1^{\text {st }}$ hull (33') & 100 & 2 & 1 \\
\hline $2^{\text {nd }}$ hull $\left(47^{\prime}\right)$ & 67 & 9 & 4 \\
\hline
\end{tabular}

Even taking into account relatively wide weight ranges $\langle 0.5,1\rangle$ for all goal functions - meaning that no solution is more than twice as important as the other(s), the solution set is reduced at least seven times. It gives an idea about the utility of the filtering tool as it enables a DM that is quite unsure about the priority of the goal function to significantly reduce the solution set that has to be evaluated manually at the end. It makes the manual evaluation of the whole Pareto set which will be inefficient and time-consuming - unnecessary.

After running the whole method (optimisation process together with MCDM), the DM can choose from a set of solutions that are not only Pareto non-dominated (equally good in terms of all three goal functions) but also non-wdominated (equally good in terms of relative importance of the goal functions set by the weight ranges). Consequently, the DM is only required to input the necessary data regarding the hull design, specify the weight ranges for the MCDM and evaluate the filtered solution set consisting of only a few individuals.

\section{DISCUSSION}

Owing to the optimisation constraints described in Optimisation Problem section, all generated solutions are feasible rig configurations.

What might be surprising, especially in case of smaller hull $(\mathrm{LOA}=10.07 \mathrm{~m})$, is the fact that there is no single rig configuration with less than 4 spreader levels among the individuals filtered from the Pareto front. It is important to notice that it is the maximum possible number of spreader levels in the algorithm. In the Pareto set (before the MCDM phase), also configurations with 3 spreader levels might be found in case of both hulls, as well as a few 2-spreader-level configurations in case of a smaller hull. However, due to significant differences regarding the $1^{\text {st }}\left(\mathrm{m}^{\star} \mathrm{VCG}\right)$ and $3^{\text {rd }}$ (rig material cost) goal functions, all those configurations were $\mathrm{w}$-dominated. It creates an interesting case as in the world of non-racing sailing - yachts of that size (especially 37') rarely happen to have more than 3 spreader levels. For a 37' mass-produced sailing yacht, it is usual to have mostly 1 or 2 spreader levels (e.g. Moody 34, Delphia 33), whereas for a $47^{\prime}$ hull, it is usually 2 or 3 spreader levels (e.g. Dehler 46, Delphia 47) [32]. There are three possible reasons for this.
The first and the most probable reason is that taking only the rig material cost (mast \& spreader profiles, wires, eye terminals and rigging screws) for the sake of cost estimation has affected the optimisation and filtering processes. That way of cost estimation favours the configurations with more spreader levels as it omits the additional cost of labour in case of more complicated rigs (more spreaders to mount and more lines to trim). On the other hand, the rig material cost is the part that does not vary so much across the world, whereas the labour cost is highly dependent on the level of economic development (and so wages) of the specific country. During future development of the method, some sort of applicability criteria will need to be considered, as increment of the rig complexity might generate more drawbacks than advantages, especially considering the pleasure yachts.

The second (less likely) explanation of 4-spreader-level solutions is the fact that taking into account mass-produced profiles for the mast, on top of the control parameter taking discrete values, makes the rig selection problem even more discrete. It is possible that the considered hulls' sizes favour the 4-spreader configurations, due to the chance that the one of the required inertia moments for the mast in case of 2 \& 3 spreader configurations happened to be slightly above the value that forces the algorithm to choose the bigger profile. The last of the possible reasons is that the rig design of the mass-produced yachts are optimised regarding largely different goal functions than those considered here: a more complicated rig requires more time and knowledge to trim well and may not always be desired. This issue is partially covered by the economic aspect mentioned in the first point, though there might be an availability issue regarding the well-qualified riggers that can successfully deal with such complicated trimming [33], [34]reducing large displacements caused by aerodynamic and inertial loads. Furthermore, since the rig is aimed at supporting sails, its deformation significantly affects aerodynamic performances, so that dock tuning has also a relevant impact on the propulsion, especially in racing. However, the complexity of the problem and the peculiarities of each different system are the causes of the lack of specific dock tuning procedures in rules and guidelines of Classification societies. The present work, developed in collaboration with the Italian shipyard Perini Navi S.p.A., consists in the validation of a dock tuning numerical procedure adopting a Finite Element Method (FEM.

\section{SUMMARY AND CONCLUSSION}

In the paper, a framework for Evolutionary Multi-Objective Optimisation of a sailing yacht rig has been presented. The method is relatively robust, integrated within one software environment and does not limit its search to a narrow predefined solution set, but it takes into account all feasible solutions within the given search space. It offers major time savings as the proposed algorithms are able to generate rig geometry, evaluate the normal forces in each of its elements, make the rig scantling, and calculate its mass, VCG and cost 
of the rig elements within a few seconds. Thus, even at this stage of development, the method may be utilised as a design tool for yacht construction when making decisions regarding the yacht rig. Based on the outcomes presented in the paper, an interesting case has been observed, the answer to which will be pursued in further research.

Despite seeing the potential of the discussed framework, it is crucial to mention the limitations of the currently presented version, which might limit the application of the method to a preliminary design stage. The first one is that its application is limited to the most common rig configuration - Bermuda sloop - and one material for the mast \& spreader profiles - an aluminium alloy. The other major limitation is a simplified rig efficiency-related objective - it might be argued that the total sail area cannot be a precise indicator for sailing rig efficiency, which is also heavily affected by sail shapes (camber, roach factor and a tip shape of the mainsail) and elongation (in terms of aerodynamics). Therefore, future development of the method will include proposing a more realistic rig efficiency-oriented objective as well as case studies of already applied rig design providing evidence in tangible terms of the solutions' quality proposed by the method. In the longer term, it is assumed to broaden the applicability of the methods for other rig configurations or possibly also other materials for mast \& spreader profiles to choose from.

\section{ACKNOWLEDGEMENTS}

This project is supported by the statutory activity No. 034159 of the Ministry of Science and Higher Education of Poland.

\section{REFERENCES}

1. C. A. Marchaj, Sailing Theory and Practice. 1964.

2. L. Larsson and R. Eliasson, Principles of Yacht Design. 2013.

3. N. L. Skene, Elements of yacht design. The Rudder Publishing Company, New York, 1904.

4. A. Karczewski and J. Kozak, "Variant designing in the preliminary small ship design process," Polish Marit. Res., vol. 24, no. 2, pp. 77-82, Jun. 2017, doi: 10.1515/ pomr-2017-0052.

5. L. Xiao, J. C. Alves, N. A. Cruz, and J. Jouffroy, "Online speed optimization for sailing yachts using extremum seeking," 2012, doi: 10.1109/OCEANS.2012.6404876.

6. S. S. Knudsen, "Sail Shape Optimization with CFD," pp. 1-118, Aug. 2013, Accessed: Sep. 12, 2020. [Online]. Available: https://findit.dtu.dk/en/catalog/2292741078.

7. A. H. Day, "Sail optimisation for maximal speed," J. Wind Eng. Ind. Aerodyn., vol. 63, no. 1-3, pp. 131-154, Oct. 1996, doi: 10.1016/S0167-6105(96)00073-6.
8. Sugimoto, "A method for optimizing sail design," Sport. Eng., vol. 2, no. 1, pp. 35-48, Feb. 1999, doi: 10.1046/j.1460-2687.1999.00017.x.

9. A. Laveron-Simavilla, V. Lapuerta, S. Franchini, and A. Sanz, "Sail optimization for upwind sailing: application in a Tornado, the Olympic class catamaran."

10. M. Biancolini, M. Sacher, and U. Cella, A CFD-based wing sail optimisation method coupled to a VPP. 2015.

11. S. Shankaran and T. Jones, "IMPROVING THE DESIGN OF SAILS USING CFD AND OPTIMIZATION ALGORITHMS,” Jun. 2020.

12. A. Zamarin, T. Matulja, and M. Hadjina, "Methodology for Optimal Mast and Standing Rigging Selection of a Racing Yacht Using AHP and FEM," Brodogradnja, vol. 64, pp. 11-21, Mar. 2013.

13. J. Wallace et al., Optimal Rig Design Using Mathematical Programming. 2006.

14. S. Malpede and F. Nasato, "A fully integrated sail-rig analysis method," RINA - Int. Conf. - Innov. High Perform. Sail. Yachts, Pap., pp. 203-210, Jan. 2010.

15. Polish Register of Shipping, "Rules for the Classification and Construction of Sea-Going Yachts, Part VII - Rig (available only in polish)," 1999. https://www.prs.pl/ uploads/jac_c7.pdf (accessed Jul. 01, 2020).

16. G. S. Lloyd, "Rules for Classification and Construction I Ship Technology 3 Special Craft 3 Yachts and Boats up to 24 m," 2003. Accessed: Jul. 29, 2020. [Online]. Available: www.gl-group.com.

17. "Rhino 6 for Windows and Mac." Accessed: Jun. 29, 2020. [Online]. Available: https://www.rhino3d.com/.

18. “Grasshopper - New in Rhino 6.” 2019, Accessed: Jun. 29, 2020. [Online]. Available: https://www.rhino3d.com/6/ new/grasshopper.

19. R. Vierlinger, "Multi Objective Design Interface," vol. 2013, no. April, pp. 1-61, 2013, doi: 10.13140/RG.2.1.3401.0324.

20. M. T. M. Emmerich and A. H. Deutz, "A tutorial on multiobjective optimization: fundamentals and evolutionary methods," Nat. Comput., vol. 17, no. 3, pp. 585-609, Sep. 2018, doi: 10.1007/s11047-018-9685-y.

21. E. Zitzler, M. Laumanns, and L. Thiele, “\{SPEA2\}: Improving the $\{\mathrm{S}\}$ trength $\{\mathrm{P}\}$ areto $\{\mathrm{E}\}$ volutionary $\{\mathrm{A}\}$ lgorithm," EUROGEN 2001. Evol. Methods Des. Optim. Control with Appl. to Ind. Probl., pp. 95-100, 2002, doi: 10.1.1.28.7571. 
22. D. E. Goldberg, Genetic Algorithms in Search, Optimization, and Machine Learning. 1989.

23. R. Vierlinger and A. Hofmann, A Framework for Flexible Search and Optimization in Parametric Design. 2013.

24. S. Bechikh, M. Kessentini, L. Ben Said, and K. Ghédira, "Preference Incorporation in Evolutionary Multiobjective Optimization: A Survey of the State-of-the-Art," Adv. Comput., vol. 98, pp. 141-207, 2015, doi: 10.1016/ bs.adcom.2015.03.001.

25. K. Deb and H. Jain, "An evolutionary many-objective optimization algorithm using reference-point-based nondominated sorting approach, Part I: Solving problems with box constraints," IEEE Trans. Evol. Comput., vol. 18, no. 4, pp. 577-601, 2014, doi: 10.1109/TEVC.2013.2281535.

26. P. K. Shukla, C. Hirsch, and H. Schmeck, "A Framework for Incorporating Trade-Off Information Using MultiObjective Evolutionary Algorithms," in Parallel Problem Solving from Nature, PPSN XI, 2010, pp. 131-140.

27. J. Szlapczynska and R. Szlapczynski, "Preference-based evolutionary multi-objective optimization in ship weather routing," Appl. Soft Comput. J., vol. 84, p. 105742, 2019, doi: 10.1016/j.asoc.2019.105742.

28. International Yacht Brokers, "s/y DISCOVERER (Challenge 67’) yacht brochure.” 2019.

29. "Navtec Catalog." https://www.oysterbayboatshop.com/ library/nav/index.html\#p=4 (accessed Jun. 30, 2020).

30. “Continuous vs Discontinuous Standing Rigging.” https:// info.upffront.com/blog/continuous-vs-discontinuousstanding-rigging (accessed Nov. 23, 2020).

31. J. Kozak and W. Tarełko, "Case study of masts damage of the sail training vessel POGORIA," Eng. Fail. Anal., vol. 18, no. 3, pp. 819-827, Apr. 2011, doi: 10.1016/j. engfailanal.2010.11.016.

32. "SailboatData.com - the worlds largest sailboat database." https://sailboatdata.com/ (accessed Aug. 05, 2020).

33. S. Ghelardi, A. Garavaglia, C. M. Rizzo, and M. Paci, "On the rig dock tuning of large sail yachts," Ocean Eng., vol. 183, pp. 384-397, Jul. 2019, doi: 10.1016/j.oceaneng.2019.04.080.

34. L. Samson and M. Kahsin, "A method to determine the tightening sequence for standing rigging of a mast," Polish Marit. Res., vol. 26, no. 4, pp. 47-55, Dec. 2020, doi: 10.2478/ pomr-2019-0065.

\section{CONTACT WITH THE AUTHORS}

Mikołaj Pawłusik

e-mail:mikpawlu@student.pg.edu.pl

Rafał Szłapczyński

e-mail:rafal.szlapczynski@pg.edu.pl

Artur Karczewski

e-mail: artur.karczewski@pg.edu.pl

Gdansk University of Technology

Narutowicza 11/12

80-233 Gdańsk,

Poland 